\title{
New journal: Chemical Synthesis
}

\author{
Bao-Lian Su, $\mathbf{u}^{1, *}$ \\ 'Laboratory of Inorganic Materials Chemistry (CMI), University of Namur, Namur B-5000, Belgium. \\ ${ }^{2}$ State Key Laboratory of Advanced technology for Materials Synthesis and Processing, Wuhan University of Technology, Wuhan \\ 430070, Hubei, China.
} ^Correspondence to: Prof. Bao-Lian Su, Laboratory of Inorganic Materials Chemistry (CMI), University of Namur, 61 rue de
Bruxelles, Namur B-5000, Belgium. E-mail: bao-lian.su@unamur.be

How to cite this article: Su BL. New journal: Chemical Synthesis. Chem Synth 2021;1:1. http://dx.doi.org/10.20517/cs.2021.01

Received: 15 Jan 2021 Accepted: 15 Jan 2021 Published: 25 Jan 2021

Academic Editor: Bao-Lian Su Copy Editor: Miao Zhang Production Editor: Jing Yu

Chemical Synthesis is an open access peer-reviewed journal publishing original research from across all areas of the chemical sciences. The journal aims to be the premier resource of seminal and insightful research as well as a showcase for researchers in both academia and industry, providing a platform of inspiration for the future of chemistry. Chemical Synthesis intends to serve as the preeminent international chemistry journal and has the ambition to be among the first choices of chemists for publication of their discoveries.

Chemical synthesis is a series of chemical reactions for the purpose of obtaining one or more known or unknown substances or materials. It is the foundation and core of organic chemistry, inorganic chemistry, medicinal chemistry, polymer chemistry, and materials chemistry. Inorganic synthesis provides a bright prospect for the development of inorganic materials. New inorganic materials have been widely used in various fields of economy, such as high temperature resistance, high pressure resistance, low temperature resistance, optics, electricity, magnetism, superconductivity, energy storage and conversion materials, etc., as well as catalytic materials that promote the development of petrochemicals. The new materials provided by synthetic chemistry enable the further development of space technology, atomic energy industry, and marine resource development. Synthetic chemistry provides many new ways to produce drugs, synthesizing sulfonamides, antibiotics, vitamins, and oral contraceptives. Many analgesics, anesthetics, preservatives, hypnotic agents, etc. are now synthesized. The close cooperation of synthetic chemistry, biology, physics, and other disciplines is expected to play an important role in conquering diseases such as cancer and mental illness, controlling heredity, and extending human life.

\footnotetext{
(@) (1)

(C) The Author(s) 2021. Open Access This article is licensed under a Creative Commons Attribution 4.0 International License (https://creativecommons.org/licenses/by/4.0/), which permits unrestricted use, sharing, adaptation, distribution and reproduction in any medium or format, for any purpose, even commercially, as long as you give appropriate credit to the original author(s) and the source, provide a link to the Creative Commons license, and indicate if changes were made.
} 
In short, synthetic chemistry can not only imitate substances found in nature, but also create substances that do not exist in nature, which play a very important role in the development of science and technology and the progress of humanity.

Chemical Synthesis will thus embrace all significant advances in chemical synthesis, theoretical and instrumental studies at the molecular and nano level, and the application of synthetic products (materials), encompassing the previously unknown and the innovative.

Chemical Synthesis is led by a team of globally well-known and enthusiastic editors who are very active in their respective fields and possess editorial experience.

\section{DECLARATIONS}

\section{Authors' contributions}

The author contributed solely to the article.

\section{Availability of data and materials}

Not applicable.

\section{Financial support and sponsorship}

None.

\section{Conflicts of interest}

The author declared that there are no conflicts of interest.

\section{Ethical approval and consent to participate}

Not applicable.

\section{Consent for publication}

Not applicable.

\section{Copyright}

(c) The Author(s) 2021. 